\title{
Foramen Magnum Meningioma: Microsurgical Endoscopic-Controlled Resection via a Lateral Suboccipital Retrocondylar Approach with Preservation of Posterior Arch of Atlas Integrity
}

\author{
Hischam Bassiouni ${ }^{1}$ \\ ${ }^{1}$ Departments of Neurosurgery, Klinikum Amberg and Klinikum \\ Weiden, Amberg, Bavaria, Germany \\ J Neurol Surg B 2019;80(suppl S4):S352-S354.
}

\begin{abstract}
Address for correspondence Hischam Bassiouni, MD, PhD, Departments of Neurosurgery, Klinikum Amberg and Klinikum Weiden, Mariahilfbergweg 7, 92224 Amberg, Bavaria, Germany (e-mail: hibassiouni@yahoo.de).
\end{abstract}

\begin{abstract}
Objective Surgical treatment of foramen magnum (FM) meningiomas is challenging due to proximity of the tumor to critical neurovascular structures, namely, the lower brainstem/upper cervical cord, vertebral artery, PICA, and lower cranial nerves. Controversies in microsurgical resection of meningiomas in this location include the necessity for condyle drilling and the need for vertebral artery mobilization. However, a laminectomy or hemilaminectomy of the C1 posterior arch is usually routinely performed. We herein present microsurgical, endoscopic-controlled resection of a FM meningioma via a posterolateral retrocondylar suboccipital craniotomy with preservation of the integrity of the posterior arch of the atlas.

Setting Our patient, a 57-year-old patient, suffered from right-sided hemiparesis due to a right-sided ventrolateral FM meningioma compromising the medulla oblongata and upper cervical cord. The tumor at the craniocervical junction was resected through a posterolateral suboccipital retrocondylar craniotomy.

Results Radical resection of the FM meningioma was accomplished via a lateral suboccipital retrocondylar craniotomy with preservation of posterior arch of atlas integrity. The postoperative course was uneventful with full preservation of neurological function. Preoperative hemiparesis subsided completely after surgery.

\section{Keywords \\ - meningioma \\ - skull base \\ - microsurgery \\ - foramen magnum \\ - neuroendoscopy}

Conclusion Anterior-laterally located FM meningiomas can be safely and completely resected via a suboccipital retrocondylar craniotomy. A laminectomy or hemilaminectomy of the posterior arch of $\mathrm{C} 1$ is not routinely required for complete and safe resection of these tumors at the craniocervical junction. Neuroendoscopy is beneficial for control of complete tumor resection.

The link to the video can be found at: https://youtu.be/DBk6qoj6OzQ.
\end{abstract}

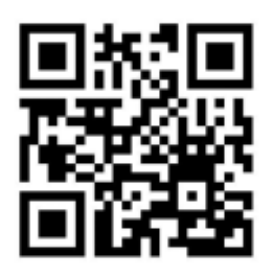

received

March 24, 2019

accepted

August 25, 2019

published online

October 22, 2019 www.thieme.com/skullbasevideos

www.thieme.com/jnlsbvideos
License terms

$10.1055 / \mathrm{s}-0039-1698822$. ISSN 2193-6331. (c) 2019 Georg Thieme Verlag KG Stuttgart · New York

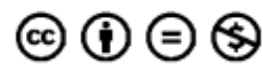




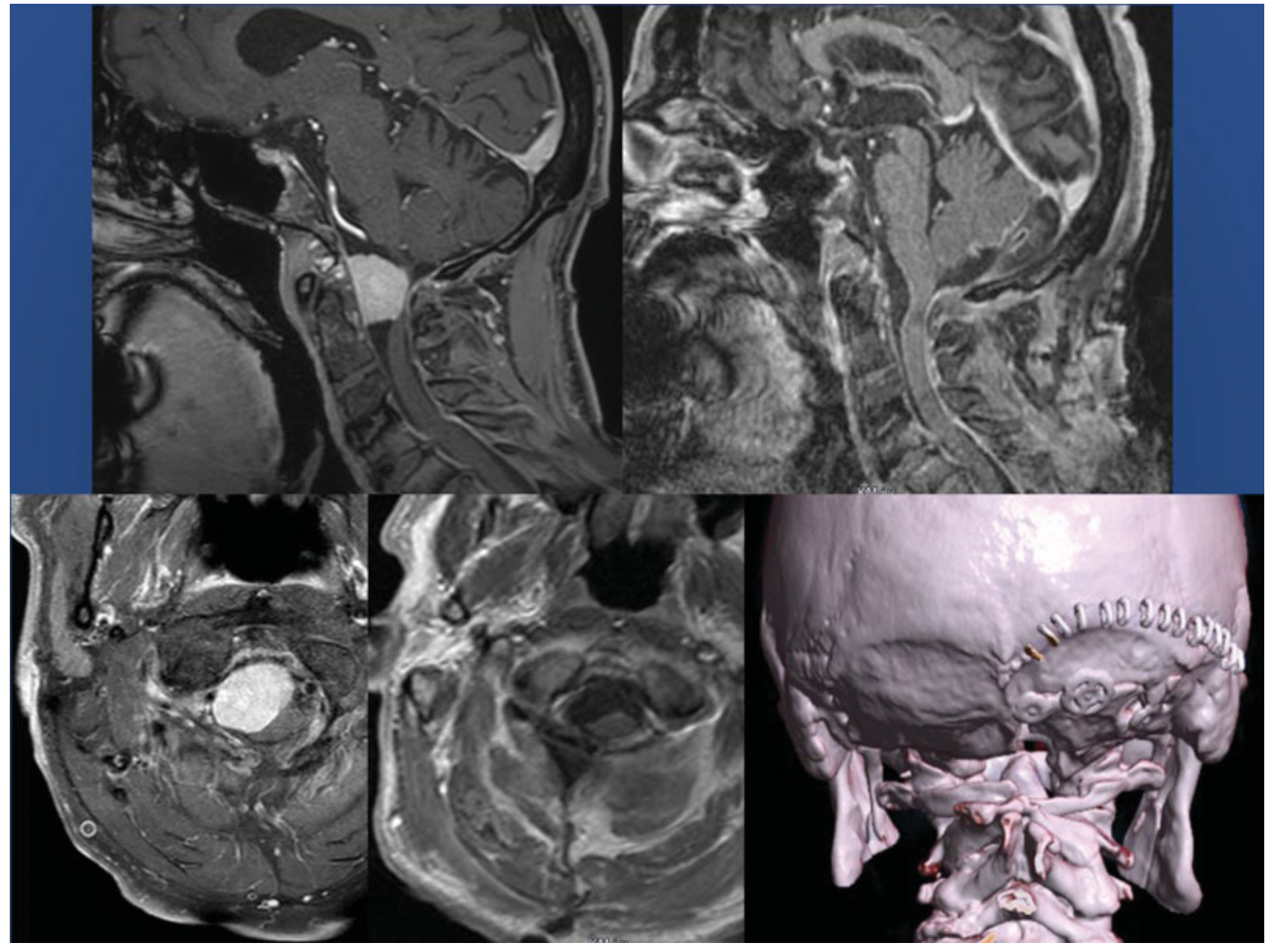

Fig. 1 Pre- and postoperative MRIs with contrast enhancement showing complete removal of foramen magnum meningioma. Postoperative 3D CT bone window displays preservation of posterior atlantal arch integrity. 3D, three-dimensional; $C T$, computed tomography; MRI, magnetic resonance imaging. 


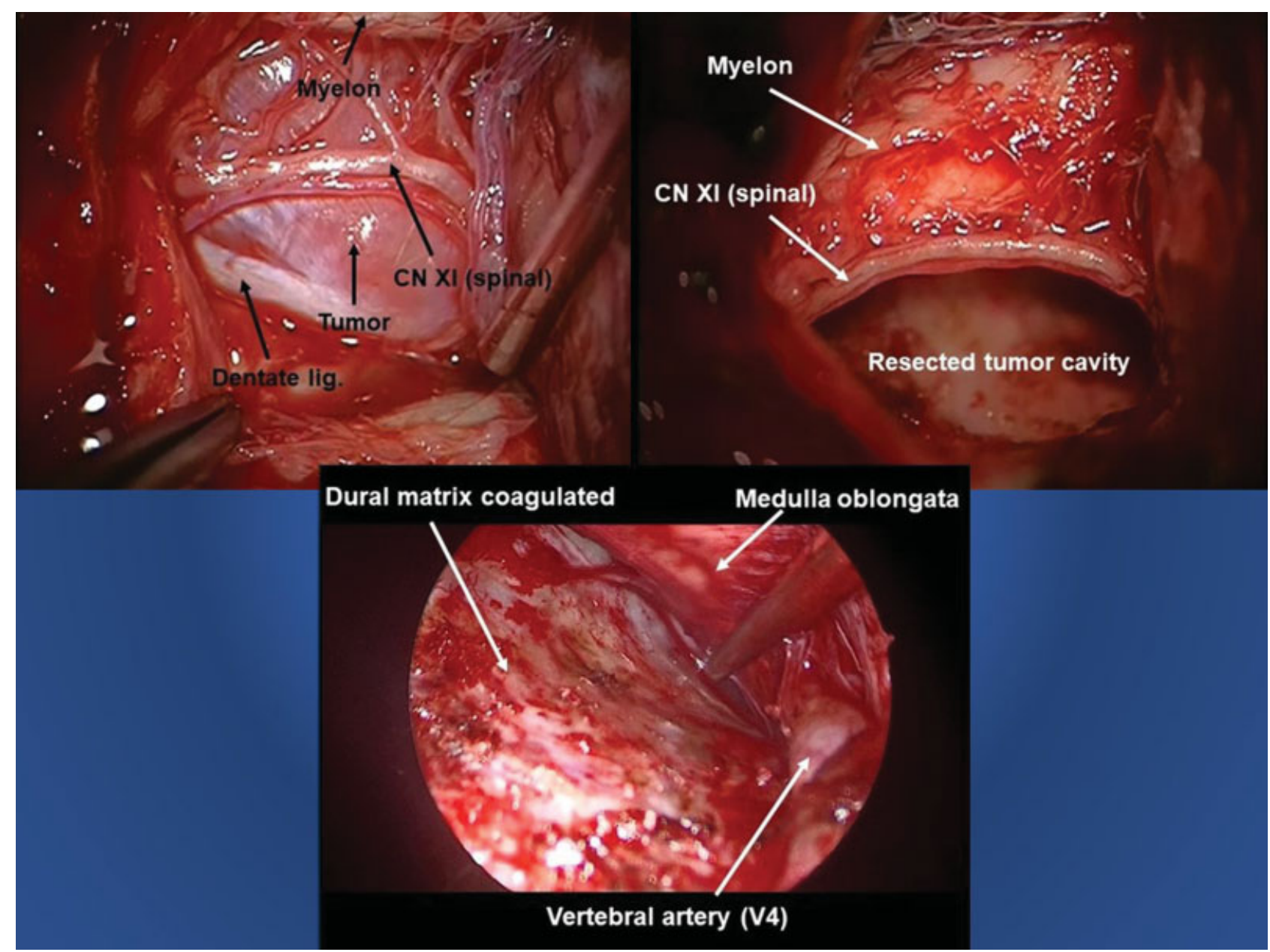

Fig. 2 Intraoperative view before and after complete tumor removal. Endoscopic control demonstrating vertebral artery. CN, cranial nerve.

\section{Publication Comments}

The authors' video is an excellent demonstration of the resection of a foramen magnum meningioma that is primarily located in the upper cervical spine canal. They have shown that the tumor can be safely resected with the removal of just a small portions the superior aspect of the lamina of $\mathrm{C} 1$ on the operated side, otherwise largely leaving the ring of $\mathrm{C} 1$ intact.

This is an interesting technique that I will keep in mind when approaching these tumors in the future.
The authors have used the straight prone position rather than the lateral position, and an inverted "J" incision rather than a curvilinear incision as I might use, but there are a number of approaches to such a lesion and the author's technique as demonstrated in the video is excellent.

Michael Chicoine, MD Washington University St. Louis, MO

Conflict of Interest

None declared. 